\title{
Exploration of Genetic Diversity in Traditional Landraces of Rice for Yield and Its Attributing Traits under Saline Stress Condition
}

\author{
P. Raghavendra ${ }^{1 *}$, B. M. Dushyantha Kumar ${ }^{1}$, H. M. Sachin Kumar ${ }^{1}$, R. Madhuri ${ }^{1}$, \\ S. Gangaprasad ${ }^{1}$, S. L. Krishna Murthy ${ }^{2}$, B. C. Dhananjaya ${ }^{3}$, B. I. Halingali ${ }^{4}$ and \\ Shailaja Hittalmani ${ }^{5}$
}
${ }^{1}$ Department of Genetics and Plant breeding, UAHS, Shivamogga-577204, Karnataka, India
${ }^{2}$ Division of crop improvement, CSSRI, Karnal-132001, Haryana, India
${ }^{3}$ Department of Soil science and agriculture chemistry, UAHS, Shivamogga-577204, Karnataka, India
${ }^{4}$ Department of Agricultural statistics, UAHS, Shivamogga-577204, Karnataka, India
${ }^{5}$ Department of Genetics and Plant breeding, UAS, Bangalore-560065, Karnataka, India

*Corresponding author

\section{A B S T R A C T}

Genetic divergence study of 144 rice landraces using Mahalanobis $\mathrm{D}^{2}$ statistics revealed the presence of considerable genetic diversity. The 144 diverse landraces were grouped

Keywords

Rice, $\mathrm{D}^{2}$ analysis, Genetic

diversity analysis,

Landraces and Salinity

Article Info

Accepted:

22 May 2018

Available Online:

10 June 2018 into 13 clusters with the cluster VI consists of maximum of 17 landraces followed by cluster XII which has 16 landraces. The maximum intra cluster distance was recorded in cluster V (969.20) followed by cluster II (917.05) indicating that the landraces included in these cluster were relatively more diverse. Among the inter cluster distances highest was recorded for cluster V and XII (5989.69) followed by cluster XI and XII (5155.12). The inter cluster distance was higher than the intra cluster distance indicating wide genetic diversity among the genotypes of different groups. For grain yield per plant, the highest cluster mean was recorded in cluster X (49.50gm) and lowest $(14.50 \mathrm{gm})$ was recorded in cluster VIII. The highest contribution towards total divergence was recorded by plant height $(52.37 \%)$ followed by spikelet per panicle $(24.88 \%)$, grain yield /plant $(11.05 \%)$. These characters are highly genetic variable and genotype having these characters in different cluster could be used in breeding programme to develop high yielding cultivars in rice under saline condition.

\section{Introduction}

Rice (Oryza sativa L.) is a one of the most important cereal crops and serves as the staple food for over one-third of the world's population (Chanbeni et al., 2012). The tremendous variation for salt tolerance within
Oryza species provide opportunities to improve rice for salt-stress tolerance through genetic means.Soil salinization is a serious problem in the entire world and it has grown substantially causing loss in crop productivity (FAO, 2006). It is a major constraint limiting agricultural productivity on nearly $20 \%$ of the 
cultivated and irrigated area worldwide (Zheng et al., 2001). The major inhibitory effect of salinity on plant growth has been attributed to osmotic effect, ion toxicity and nutritional imbalance leading to reduction in photosynthetic activities and other physiological disorders. Salt stress has been reported to cause an inhibition of growth and development, reduction in photosynthesis, respiration and protein synthesis in sensitive species. According to the classification of crop tolerance to salinity, the rice crop is within the sensitive division from 0 to $8 \mathrm{ds} \mathrm{m}^{-}{ }^{1}$.The susceptibility of rice to salinity stress varies with growth stages. It was reported that the panicle formation and tillering stages were the most sensitive stages to salinity.

It was hypothesized that rice yield decreased by 12 per cent for every unit $\left(\mathrm{dSm}^{-1}\right)$ increase in EC above $3 \mathrm{dSm}^{-1}$. The highest yield was obtained from fresh water (no salinity) while salinity treatments of 2, 4, 6 and $8 \mathrm{dSm}^{-1}$ represented 21, 25, 37 and 47 per cent yield losses. (Ologundudu et al., 2014). Therefore, the present study is planned to exploit the diversity of landraces for salinity tolerance and their characterization. The strength and value of germplasm depends on two factors, the number of accessions it contains and the diversity present in those accessions (Sridhar et al., 2016). For the balanced use of plant genetic resources, characterization and quantification and information on the genetic diversity within and among closely related crop varieties is essential. Genetic diversity is prerequisites for any successful breeding programme. Use of genetically diverse parents in recombination breeding supposed to give maximum heterosis in $\mathrm{F}_{1}$ 's and the importance of genetic diversity in selecting the parents has been continually emphasized by lot of workers (Thippeswamy et al., 2016, Anandan et al., 2011, Dushyanthakumar and Anand, 2010). Thus, the evaluation of genetic diversity of rice genotypes could provide valuable information for genetic improvement of salt tolerant rice.

\section{Materials and Methods}

\section{Experimental location}

The material for the present investigation contained 144landraces of rice conserved at the in the Department of Genetics and Plant breeding, UAHS, Shivamogga, Karnataka. The experiment was carried out in natural saline field (pH: 8.14, EC: $5.81 \mathrm{dsm}^{-1}$, ESP: 9.21) condition during kharif season of 2016.

\section{Field evaluation and data collection}

The experiment was laid out in augmented design with three replications. For each landrace, 20 plants with row to-row spacing of $25 \mathrm{~cm}$ and plant-to-plant spacing of $10 \mathrm{~cm}$. Recommended package of practices were followed to raise a healthy crop. The data on ten quantitative characters were recorded on five competitive plants of each landrace. Data were collected on Days to $50 \%$ flowering, SPAD reading, total number of tillers /plant, productive tillers /plant, plant height at maturity $(\mathrm{cm})$, panicle length $(\mathrm{cm})$, panicle weight $(\mathrm{g})$, number of spikelet's/panicle, spikelet fertility (\%) and grain yield /plant (g). Data analysis was carried out using WINDOSTAT software (Version 9.2) with D ${ }^{2}$ statistics given by Mahalanobis (1936). The mean values were computed to calculate $\mathrm{D}^{2}$ values between all possible pairs of genotypes. The grouping of genotypes was done using Tocher's method as described by Rao (1952).

\section{Results and Discussion}

Genetic divergence among 144 landraces for 10 characters was studied by using Mahalanobis $\mathrm{D}^{2}$ analysis as per Rao (1952). Based on Mahalanobis $\mathrm{D}^{2}$ analysis, the 144 landraces for yield and related characters were 
grouped in to 13 clusters. The distribution pattern of landraces in 13 clusters are presented in Table 24. The cluster pattern revealed that cluster VI consists of maximum of 17 landraces followed by cluster XII which has 16 landraces. The lowest number of landraces i.e, four were included in cluster VIII. Similarly Dushyanthakumar (2008), Kaliyamoorthy et al., (2013) and Kumari et al., (2018) observed diversity among the rice genotypes for yield and its attributing traits.

The distances for the landraces with respect to yield within the cluster and also the distance of two clusters were assessed. The average $\mathrm{D}^{2}$ values of intra and inter clusters distances were presented in Table 2. The maximum intra cluster distance was recorded in cluster V (969.20) followed by cluster II (917.05) indicating that the landraces included in these cluster were relatively more diverse and the lowest intra cluster distance was observed in cluster IX (148.21) followed by cluster XII (286.13) indicating that landraces present in these clusters were relatively less diverse. Among the inter cluster distances highest was recorded for cluster V and XII (5989.69) followed by cluster XI and XII (5155.12), cluster VII and XII (5107.60) indicating that landraces in these 2 respective clusters were highly diverse. Whereas, the lowest inter cluster distance were recorded between cluster IV and cluster V (660.56) followed by cluster XI and XIII (857.26) indicating that the landraces belong to these two respective clusters were relatively less diverse. Similar pattern of diversity was reported by Dushyanthakumar (2008), Kaliyamoorthy et al., (2013) and Kumari et al., (2018). The higher the intra cluster distance indicates that the landraces present in respective clusters and inter cluster distances between respective clusters have wider genetically distance between them and landraces which falls under the more far distance showing clusters had wider diversity between them. Importantly, the genotypes belonging to the highly diverged clusters should be used in hybridization programme for obtaining a wide spectrum of variations in the breeding population Nirosha et al., (2016). On the other hand, Shahidullah et al., (2009) suggested the selection of genotypes belonging to moderate diversity in order to exploit benefits of heterosis. Above all, the selection of genotypes is dependent on the objectives of the breeding programme.

\section{Cluster mean analysis}

The cluster means with respect to ten yield and yield related traits were calculated using touchers method and are presented in Table 3. For days to $50 \%$ flowering higher cluster mean was recorded for cluster XI and XIII (136.00) and lowest cluster mean was recorded in cluster IX (81.00). Regarding the SPAD reading, highest cluster mean was recorded for cluster VII (17.50) and lowest cluster mean was recorded in cluster $\mathrm{X}$. For total no. of tillers/plant, highest cluster mean was observed in cluster $X$ (25.00) on the contrary, the lowest cluster mean was recorded for cluster XI (7.50). However, in productive tillers/plant, the highest cluster mean was recorded for cluster X (24.80) and lowest cluster mean was recorded for cluster XI (7.42). Whereas, for plant height, the highest cluster mean was recorded for cluster XII $(139.50 \mathrm{~cm})$ and lowest cluster mean was observed in cluster V $(75.29 \mathrm{~cm})$. Similarly, for panicle length, highest cluster mean was recorded for cluster XII $(24.67 \mathrm{~cm})$ and lowest cluster mean was recorded in cluster XIII (18.00). Whereas, for panicle weight, highest cluster mean was recorded in cluster VI $(2.92 \mathrm{gm})$ and lowest cluster mean was recorded in cluster VIII (0.74gm). For spikelets/panicle, the highest cluster mean was recorded for cluster VII (178.60) and lowest cluster mean was recorded for cluster VIII (121.00). 
Table.1 Grouping of 144 landraces based on $D^{2}$ clustering method evaluated during Kharif 2016 for yield and related traits under saline condition

\begin{tabular}{|c|c|c|}
\hline Cluster & $\begin{array}{l}\text { Number of } \\
\text { Landraces }\end{array}$ & Landraces* \\
\hline $\mathbf{I}$ & 11 & $\begin{array}{l}\text { SGRL1, SGRL8, SGRL11, SGRL19, SGRL43, SGRL53, SGRL62, } \\
\text { SGRL160, SGRL162, SGRL169, SGRL177 }\end{array}$ \\
\hline II & 12 & $\begin{array}{l}\text { SGRL6, SGRL17, SGRL22, SGRL31, SGRL34, SGRL74, } \\
\text { SGRL94, SGRL109, SGRL130, SGRL133, SGRL148, SGRL150 }\end{array}$ \\
\hline III & 14 & $\begin{array}{l}\text { SGRL10, SGRL23, SGRL25, SGRL29, SGRL33, SGRL47, } \\
\text { SGRL48, SGRL50, SGRL67, SGRL69, SGRL73, SGRL 91, } \\
\text { SGRL115, SGRL124 }\end{array}$ \\
\hline IV & 9 & $\begin{array}{l}\text { SGRL24, SGRL56, SGRL78, SGRL84, SGRL105, SGRL123, } \\
\text { SGRL151, SGRL155, SGRL159 }\end{array}$ \\
\hline $\mathbf{V}$ & 10 & $\begin{array}{l}\text { SGRL9, SGRL15, SGRL20, SGRL26, SGRL60, SGRL70, } \\
\text { SGRL125, SGRL134, SGRL142, SGRL144 }\end{array}$ \\
\hline VI & 17 & $\begin{array}{l}\text { SGRL5, SGRL7, SGRL16, SGRL18, SGRL30, SGRL37, SGRL39, } \\
\text { SGRL71, SGRL77, SGRL83, SGRL111, SGRL113, SGRL116, } \\
\text { SGRL122, SGRL138, SGRL167, SGRL175 }\end{array}$ \\
\hline VII & 7 & $\begin{array}{l}\text { SGRL45, SGRL46, SGRL64, SGRL65, SGRL68, SGRL82, } \\
\text { SGRL85 }\end{array}$ \\
\hline VIII & 4 & SGRL32, SGRL72, SGRL98, SGRL135 \\
\hline IX & 12 & $\begin{array}{l}\text { SGRL12, SGRL44, SGRL51, SGRL52, SGRL54, SGRL57, } \\
\text { SGRL59, SGRL79, SGRL96, SGRL108, SGRL121, SGRL176 }\end{array}$ \\
\hline $\mathbf{X}$ & 5 & SGRL2, SGRL35, SGRL97, SGRL132, SGRL140 \\
\hline XI & 13 & $\begin{array}{l}\text { SGRL3, SGRL4, SGRL36, SGRL93, SGRL119, SGRL126, } \\
\text { SGRL145, SGRL147, SGRL149, SGRL156, SGRL158, SGRL171, } \\
\text { SGRL174 }\end{array}$ \\
\hline XII & 16 & $\begin{array}{l}\text { SGRL14, SGRL27, SGRL41, SGRL42, SGRL49, SGRL61, } \\
\text { SGRL76, SGRL81, SGRL95, SGRL100, SGRL120, SGRL129, } \\
\text { SGRL153, SGRL154, SGRL 161, SGRL164 }\end{array}$ \\
\hline XIII & 14 & $\begin{array}{l}\text { SGRL13, SGRL 21, SGRL38, SGRL63, SGRL75, SGRL80, SGRL } \\
\text { 92, SGRL127, SGRL128, SGRL131, SGRL152, SGRL168, } \\
\text { SGRL172, SGRL173 }\end{array}$ \\
\hline
\end{tabular}


Table.2 Average intra and inter cluster distance values of landraces of rice for yield and related traits under saline condition Kharif 2016

\begin{tabular}{|c|c|c|c|c|c|c|c|c|c|c|c|c|c|}
\hline & $\begin{array}{c}\text { Cluster } \\
\text { I }\end{array}$ & $\begin{array}{c}\text { Cluster } \\
\text { II }\end{array}$ & $\begin{array}{c}\text { Cluster } \\
\text { III }\end{array}$ & $\begin{array}{c}\text { Cluster } \\
\text { IV }\end{array}$ & $\begin{array}{c}\text { Cluster } \\
\text { V }\end{array}$ & $\begin{array}{c}\text { Cluster } \\
\text { VI }\end{array}$ & $\begin{array}{c}\text { Cluster } \\
\text { VII }\end{array}$ & $\begin{array}{c}\text { Cluster } \\
\text { VIII }\end{array}$ & $\begin{array}{c}\text { Cluster } \\
\text { IX }\end{array}$ & $\begin{array}{c}\text { Cluster } \\
\text { X }\end{array}$ & $\begin{array}{c}\text { Cluster } \\
\text { XI }\end{array}$ & $\begin{array}{c}\text { Cluster } \\
\text { XII }\end{array}$ & $\begin{array}{c}\text { Cluster } \\
\text { XIII }\end{array}$ \\
\hline Cluster I & 773.00 & 1526.04 & 1281.25 & 1226.31 & 1951.21 & 1245.03 & 2308.11 & 1404.69 & 1235.87 & 1731.52 & 1636.39 & 2624.83 & 2700.00 \\
\hline Cluster II & & 917.05 & 1879.66 & 3307.36 & 4220.96 & 2505.57 & 2925.93 & 1826.51 & 1479.61 & 2062.06 & 2014.87 & 1767.90 & 3624.80 \\
\hline Cluster III & & & 297.42 & 1470.98 & 1931.33 & 2628.28 & 265.81 & 3441.12 & 1053.43 & 1723.08 & 1781.39 & 3623.71 & 1617.67 \\
\hline Cluster IV & & & & 391.81 & 660.56 & 1062.99 & 2123.71 & 2721.78 & 2047.20 & 1603.37 & 2414.93 & 4391.81 & 2297.01 \\
\hline Cluster V & & & & & 969.20 & 2154.41 & 2397.33 & 3407.45 & 3247.96 & 2654.34 & 2504.94 & 5989.69 & 2201.53 \\
\hline Cluster VI & & & & & & 426.15 & 3943.36 & 1842.41 & 1942.83 & 1353.60 & 3169.97 & 1988.19 & 4493.80 \\
\hline Cluster VII & & & & & & & 649.46 & 5033.97 & 2142.96 & 2116.20 & 2217.88 & 5107.60 & 1301.46 \\
\hline Cluster VIII & & & & & & & & 842.13 & 2715.21 & 2988.49 & 1856.24 & 2871.08 & 4196.99 \\
\hline Cluster IX & & & & & & & & & 148.21 & 1973.23 & 3402.89 & 1673.75 & 4401.13 \\
\hline Cluster X & & & & & & & & & & 341.28 & 2735.38 & 1889.45 & 2768.74 \\
\hline Cluster XI & & & & & & & & & & & 326.45 & 5155.12 & 857.26 \\
\hline Cluster XII & & & & & & & & & & & & 286.13 & 7232.85 \\
\hline Cluster XIII & & & & & & & & & & & & & 304.62 \\
\hline
\end{tabular}

*Diagonal values indicate intra cluster distances and above diagonal values indicate inter cluster distances 
Table.3 Cluster means for yield and yield related traits of 144 landraces under saline condition

\begin{tabular}{|c|c|c|c|c|c|c|c|c|c|c|}
\hline & $\begin{array}{c}\text { Days to } \\
50 \% \\
\text { flowering }\end{array}$ & $\begin{array}{l}\text { SPAD } \\
\text { reading }\end{array}$ & $\begin{array}{l}\text { Total } \\
\text { tillers }\end{array}$ & $\begin{array}{c}\text { Productive } \\
\text { tillers }\end{array}$ & $\begin{array}{c}\text { Plant } \\
\text { height } \\
\text { (cm) }\end{array}$ & $\begin{array}{l}\text { Panicle } \\
\text { length } \\
\text { (cm) }\end{array}$ & $\begin{array}{c}\text { Panicle } \\
\text { weight } \\
\text { (g) }\end{array}$ & $\begin{array}{c}\text { Spikelet } \\
\text { per } \\
\text { panicle }\end{array}$ & $\begin{array}{c}\text { Spikelet } \\
\text { fertility } \\
(\%)\end{array}$ & $\begin{array}{c}\text { Grain } \\
\text { yield/plant } \\
\text { (g) }\end{array}$ \\
\hline Cluster I & 102.78 & 9.61 & 11.90 & 11.83 & 108.06 & 21.11 & 2.03 & 140.76 & 83.43 & 22.40 \\
\hline Cluster II & 109.88 & 10.04 & 13.19 & 13.01 & 129.95 & 22.04 & 2.29 & 153.30 & 83.08 & 27.13 \\
\hline Cluster III & 101.00 & 16.60 & 10.50 & 10.24 & 97.50 & 21.83 & 1.90 & 167.50 & $80.20 * *$ & 20.00 \\
\hline Cluster IV & 97.00 & 4.30 & 13.00 & 12.81 & 81.00 & 18.50 & 2.10 & 137.00 & 85.20 & 27.25 \\
\hline Cluster V & 104.42 & 10.85 & 13.52 & 13.22 & $75.29 * *$ & 19.83 & 1.49 & 137.44 & 81.88 & 20.05 \\
\hline Cluster VI & 94.00 & 10.35 & 15.00 & 14.30 & 104.00 & 22.17 & $2.92 *$ & 124.00 & $80.20 * *$ & 43.75 \\
\hline Cluster VII & 107.00 & $17.50 *$ & 12.00 & 11.73 & 88.00 & 23.90 & 1.85 & $178.60 *$ & 81.50 & 22.25 \\
\hline Cluster VIII & 115.00 & 5.95 & 19.50 & 19.16 & 124.00 & 24.00 & $0.74 * *$ & $121.00 * *$ & $88.50 *$ & $14.50 * *$ \\
\hline Cluster IX & $81.00 * *$ & 8.55 & 11.50 & 11.25 & 117.50 & 22.15 & 2.04 & 157.00 & 88.20 & 23.50 \\
\hline Cluster X & 106.00 & $2.74 * *$ & $25.00^{*}$ & $24.80 *$ & 102.00 & 20.50 & 1.98 & 154.00 & 83.51 & $49.50 *$ \\
\hline Cluster XI & $136.00^{*}$ & 12.15 & $7.50 * *$ & $7.42 * *$ & 104.00 & 24.50 & 2.27 & 147.00 & 86.51 & 17.00 \\
\hline Cluster XII & 88.00 & 10.90 & 24.50 & 24.21 & $139.50 *$ & $24.67 *$ & 1.97 & 145.00 & 80.50 & 48.21 \\
\hline Cluster XIII & $136.00^{*}$ & 6.25 & 11.00 & 10.73 & 82.00 & $18.00 * *$ & 1.66 & 163.00 & 82.80 & 18.25 \\
\hline
\end{tabular}

*Highest cluster mean and ** Lowest cluster mean 
Table.4 Per cent contribution of yield and related characters towards divergence in landraces of rice under saline condition

\begin{tabular}{|c|l|c|}
\hline Sl.no. & \multicolumn{1}{|c|}{ Characters } & Contribution (\%) \\
\hline 1 & Plant height & $52.37 \%$ \\
\hline 2 & Spikelet per panicle & $24.88 \%$ \\
\hline 3 & Grain yield & $11.05 \%$ \\
\hline 4 & Days to 50\% flowering & $7.70 \%$ \\
\hline 5 & Total tillers & $1.78 \%$ \\
\hline 6 & SPAD reading & $1.07 \%$ \\
\hline 7 & Spikelet fertility & $0.77 \%$ \\
\hline 8 & Panicle weight & $0.18 \%$ \\
\hline 9 & Panicle length & $0.11 \%$ \\
\hline 10 & Productive tillers & $0.09 \%$ \\
\hline
\end{tabular}

For spikelet fertility, the highest cluster mean was recorded in cluster VIII (88.50) and lowest cluster mean in cluster III, cluster IV and cluster VI (80.20). Whereas, for grain yield per plant, the highest cluster mean was recorded in cluster $X(49.50 \mathrm{gm})$. Whereas, lowest $(14.50 \mathrm{gm})$ was recorded in cluster VIII. Similarly, Supriya et al., (2017), Sridhar et al., (2016) and Rathod et al., (2017) also reported varied cluster means for yield and related characters in rice genotypes. Analysis of cluster means helps to identify clusters having different levels of variability for different characters. It is possible to identify clusters having higher diversity for more no of characteristics and it also helps to identify clusters having less diversity for more number of characteristics. Utilization of higher mean recorded clusters in breeding programme is expected to yield desirable lines in advanced generation of selection.

\section{Contribution of different characters towards divergence}

Contribution of different yield and yield related traits studied towards total divergence was assessed and presented in Table 4. The highest contribution towards total divergence was recorded by plant height (52.37\%) followed by spikelet per panicle $(24.88 \%)$, grain yield /plant (11.05\%), days to $50 \%$ flowering $(7.70 \%)$ and the productive tillers/plant (0.09\%) was lowest percent contributed. These findings are in close correspondence with Chanbeni et al., (2012), Sowmiya and Venkatesan (2017) and Kumari et al., (2018).

From the above all findings it can be concluded that, The landraces studied were found to be highly diverse under saline stress, landraces from high divergent clusters contain wide genetic diversity for different traits studied and are expected to yield potential $F_{1} S$ and transgressive seggregants for further exploitation.

\section{References}

Anandan, A., Eswaran, R. and Prakash, M. 2011. Diversity in rice genotypes under salt affected soil based on multivariate analysis. Pertanika Journal of Tropical Agricultural Science, 34 (1):33-40.

Chanbeni, Y. O., Lal, G. M. and Prashant, K. R. 2012. Studies on genetic diversity in Rice 
(Oryza sativa L.). J. Agric. Sci., 8(3): 10591065.

Dushyanthakumar, B. M. 2008. Genetic divergence in red Rice (Oryza sativa $\mathrm{L}$ ). Karnataka J. Agric. Sci., 21 (3): 346-348.

Dushyanthakumar, B. M. and Anand, K. 2010. Genetic divergence in rice accessions of hill zone of Karnataka. Electron J. Plant Breeding, 1 (5): 1329-1331.

FAO. 2006. Species description - Oryza sativaL. www.fao.org

Kaliyamoorthy, S., Thirumeni, S., Paramasivam, K. and Nadaradjan, S. 2013. Genetic diversity analysis of rice (Oryza sativa) genotypes for seedling characters under saline - alkaline condition. Electronic Journal of Plant Breeding, 4(1): 1034-1042.

Kumari, P., Archana, D., Ranjan, D., Saket, D., Ram Kand, D. K. And Dwivedi, 2018. Genetic divergence in indigenous and exotic Rice (Oryza sativa L.) under SalineAlkali Condition. Int.J.Curr.Microbiol.App.Sci, 7: 4546-4553.

Mahalanobis, P. C. 1936. A study on the generalized distance in statistics. Proc. Nat. Acad. Sci. India., 2: 49-55.

Nirosha, R. Thippeswamy, I, S., Ravindrababu, V. Ram Reddy, V. and Spandana, B. 2016. Genetic diversity analysis of Zinc, Iron, Grain Protein content and yield components in Rice. Electronic journal of plant breeding, 7(2): 371-377.

Ologundudu, A. F., Adelusi, A. A. and Akinwale, R. O. 2014. Effect of salt stress on germination and growth parameters of rice (Oryza sativa L.), Not. Sci. Biol., 6(2):23724.

Rao, C. R., 1952. Advanced statistics methods in biometry, John Wiley, New York, pp. 357369.
Rathod, A. J., Mistry, P. M., Pampaniya, A. G. Patel H. R. and Chetariya C. P. 2017. D ${ }^{2}$ statistics for grain yield and quality traits in Rice (Oryza sativa L.), Int. J. Pure App. Biosci., 5(4): 54-58.

Shahidullah, S. M., Hanafi, M. M., Ashrafuzzaman, M., Razi Ismail M. and Khair, A. 2009. Genetic diversity in grain quality and nutrition of aromatic rice. African Journal of Biotechnology, 8 (7): 1238-1246.

Sowmiya, C.A. and Venkatesan, M. 2017. Studies on Genetic diversity in Rice (Oryza sativa L.). Int.J.Curr.Microbiol.App.Sci., 6(9): 1749-1756.

Sridhar, T. C., Dushyanthakumar, B. M., Mani, B. R. and Nishanth, G. K. 2016. Genetic diversity, variability and association analysis for yield traits in traditional rice (Oryza sativa L.) cultivars of southern Karnataka. Green Farming, 12(2).20-24.

Supriya, K., Vanisri, S., Jagadeeswar, R. and Sreedhar, M. 2017. Genetic diversity for yield, its contributing characters in rice (Oryza sativa L.), Agric. Update, 12(2): 589-592.

Thippeswamy, S., Chandramohan, Y., Srinivas, B. and Padmaja, D. 2016. Selection of diverse parental lines for heterotic hybrid development in rice (Oryza sativa L.).SABRAO J. Breed. Gen., 48(3): 284295.

Zheng, L., Shannon, M.C. and Lesch, S.M. 2001. Timing of salinity stress affecting rice growth and yield components. Agri. Water Managem., 48: 191-206.

\section{How to cite this article:}

Raghavendra P., B. M. Dushyantha Kumar, H. M. Sachin Kumar, R. Madhuri, S. Gangaprasad, S. L. Krishna Murthy, B. C. Dhananjaya, B. I. Halingali and Shailaja Hittalmani. 2018. Exploration of Genetic Diversity in Traditional Landraces of Rice for Yield and Its Attributing Traits under Saline Stress Condition. Int.J.Curr.Microbiol.App.Sci. 7(06): 3359-3366.

doi: https://doi.org/10.20546/ijcmas.2018.706.394 